Abstract EPV218/\#551 Table 1 Logistic regression for prediction of MI-IDS

\begin{tabular}{|c|c|c|c|c|}
\hline Variables & OR (95\% CD & P.ralues & OR (95\% CD & P-xalus \\
\hline 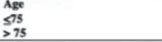 & $3.63(180.732)$ & ه..001 & $1.99(0.60-3.71)$ & 0.382 \\
\hline $\begin{array}{l}\text { BMII } \\
230 \\
230\end{array}$ & ${ }_{0.96}^{1}(0.56-1.67)$ & 0.904 & & \\
\hline $\begin{array}{l}\text { BRCA } \\
\text { Wild-ove } \\
\text { Mutatioo }\end{array}$ & $1.170 .63-2.16$ & 0.616 & & \\
\hline $\begin{array}{l}\mathrm{CCI} \\
>3 \\
>3\end{array}$ & $1.16(0.72-187)$ & 0.524 & & \\
\hline $\begin{array}{l}\text { Cal125 resposese } \\
\text { CR } \\
\text { PRSD }\end{array}$ & $186(1.14-3.30)$ & 0.012 & $2.23(1.21-4.11)$ & 0.010 \\
\hline $\begin{array}{l}\text { Mosisperience } \\
\text { No } \\
\text { Yes } \\
\text { Oos }\end{array}$ & $\begin{array}{c}1 \\
3.76(228-6.19)\end{array}$ & 8001 & $627025.1208)$ & $\$ .001$ \\
\hline $\begin{array}{l}\text { No } \\
\text { Nos } \\
\text { Yos }\end{array}$ & $1123(6.35-19.86)$ & $\infty .001$ & $856(4.22 \cdot 17.33)$ & 80.001 \\
\hline $\begin{array}{l}\text { Peritoneal sites involvement } \\
\text { i2 } \\
\geqslant 2\end{array}$ & $504(258.986)$ & $\infty .001$ & $3.11(1.45-6.65)$ & 0.003 \\
\hline
\end{tabular}

Abbreviations: BMI: body mass index; CCl: Charlson Comorbididty Index; CR: complete response; PR: partial response; $S D=$ stable disease

four significant perioperative variables according to logistic regression. The calibration plot demonstrated good agreement between the predicted and actual probability of MI-IDS $(\mathrm{p}=0.93$, Hosmer-Lemeshow test $)$.

Conclusions A nomogram might represent a useful tool to choose the best surgical approach in patients with AOC undergoing IDS.

\section{EPV219/\#581 FULL SYSTEMATIC LYMPHADENECTOMY FOR APPARENT EARLY STAGE OVARIAN CANCER: IMPACT ON SPECIFIC LYMPHATIC MORBIDITY}

E Ervas*, M Longo, A Lembo, V Artuso, A Di Siena, F Ghezzi, J Casarin. Women's and children hospital F. Del Ponte Hospital - University of Insubria, Obstetrics and Gynecology, varese, Italy

\subsection{6/ijgc-2021-IGCS.290}

Objectives To evaluate the rate of lymphatic-related morbidity among patients undergoing surgical staging for apparent earlystage ovarian cancer (EOC) and to report the specific patients' lymphatic complications.

Methods Data of consecutive patients who underwent surgical staging for EOC between 01/2002 and 12/2018 were analyzed. A self-reported validated 13-item lymphedema screening questionnaire was sent to evaluate specific lymphatic complications. Patients were stratified by the performance retroperitoneal staging into two groups: fully pelvic and aortic lymphadenectomy performed (LND) vs. no retroperitoneal staging (NO-LND). Patients who had conservative treatment were included in the study. The analysis focused only on women who answered the specific questionnaire. Patients lost

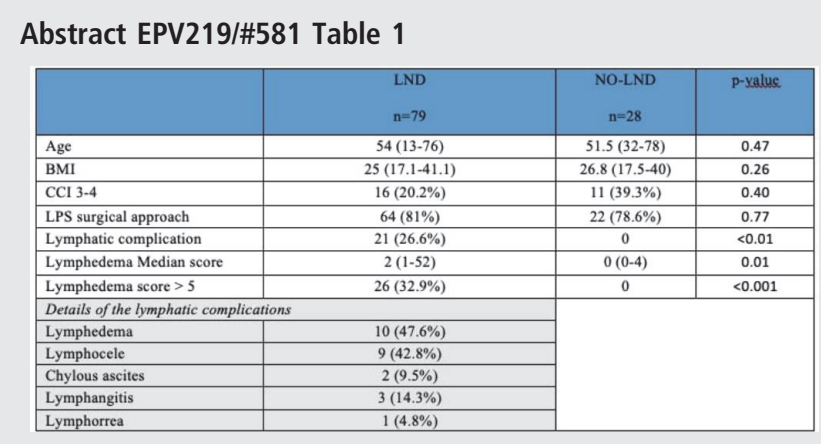

at follow-up and those who reported peripheral vascular disease at the time of surgery were excluded.

Results During the study period 140 patients were treated; according to the inclusion/exclusion criteria 107 represented our study population. Baseline characteristics such as age, BMI, Charlson Comorbidity Index (CCI) and surgical approach did not significantly differ between the groups. Patients in LND group (compared to NO-LND) had a higher rate of specific lymphatic complications $(26.6 \%$ vs. $0 \%$, p <0.01). The performance of lymphadenectomy significantly impacted the subjective lymphatic-related morbidity (score $>5$ ).

Conclusions Our study confirms a high correlation between the performance of LND and specific lymphatic morbidity in patients undergoing surgical staging for EOC. The dedicated 13 -item screening questionnaire might be a useful tool to categorize patients' perception of lymphatic-related complications, including lower extremity lymphedema.

\section{EPV220/\#594 MESONEPHRIC-LIKE MULLERIAN ADENOCARCINOMA OF THE OVARY}

${ }^{1} \mathrm{~A}$ Michas*, ${ }^{2} \mathrm{~T}$ Akrivos, ${ }^{2} \mathrm{P}$ Giannakas, ${ }^{1} \mathrm{E}$ Arvanitou, ${ }^{1} \mathrm{~K}$ Gkikas, ${ }^{1} \mathrm{~A}$ Kolomitrousi, ${ }^{1} \mathrm{C}$ Kagkaras, ${ }^{1} \mathrm{M}$ Gkiaouraki, ${ }^{1} \mathrm{~K}$ Mpalasis, ${ }^{1} \mathrm{C}$ Christofilakis, ${ }^{1} \mathrm{~N}$ Tsoukalas. ${ }^{1} 401 \mathrm{GMHA}$, Oncology, Athens, Greece; ${ }^{2} 401$ GMHA, Gynecology, Athens, Greece

\subsection{6/ijgc-2021-IGCS.291}

Objectives INTRODUCTION: Mesonephric-like Mullerian adenocarcinomas of the ovaries are extremely rare gynecological malignancies. Their embryological and histological origin remains debatable. The more prevalent tumorigenic theories support either development from Mesonephric duct remnants of the female genital tract, or development from Mullerian lesions that undergo Mesonephric differentiation.

Methods Case-report of a patient with ovarian Mesonephriclike Mullerian adenocarcinoma.

Results CASE REPORT: 64 years old female patient with medical history of hypothyroidism and dyslipidemia. During annual gynecological US-screening examination, a solid formation ( $4 \mathrm{~cm}$ diameter) was found on the left ovary. An ensuing MRI tomography diagnosed a solid ovarian mass. Further staging with CTs and PET-CT scan excluded distant neoplasmatic dissemination. Subsequently, surgical total hysterectomy was performed. After histological evaluation, the analysis concluded to low-grade Mesonephric-like Mullerian adenocarcinoma of left ovary, adjacent to multiple foci of endometriosis. Due to tumor rarity, the histological results were re-checked and verified by multiple histology experts. The patient received adjuvant chemotherapy with 6 circles of Carboplatin/paclitaxel. Treatment was completed without significant side-effects, except for mild nausea and hand-foot syndrome. Follow-up examinations showed complete disease-remission. Currently, the patient is regularly monitored with scheduled-periodic assessments, without any sign of recurrence. Moreover molecular analysis revealed heterozygous somatic KRAS mutation NM_033360.4:c.35G>A:p.(Gly12Asp), and heterozygous genomic PMS2 mutation NM_000535.7:c.2559C > G p.(Ile853Met)

Conclusions CONCLUSION: Mesonephric-like Mullerian adenocarcinomas of ovaries are extremely rare tumors $(<15$ literature reports in Pubmed, Scopus). The most prevalent theory of tumorigenesis, involves cancer development from Mullerian lesions (eg foci of endometriosis) that undergo Mesonephric differentiation. Further research is necessary to illuminate the neoplastic nature of these lesions. 